\title{
Galectin-10 Is Released in the Nasal Lavage Fluid of Patients with Aspirin-Sensitive Respiratory Disease
}

\author{
Ma. Cristina Negrete-Garcia, ${ }^{1}$ Carla Yoneli Jiménez-Torres, ${ }^{1}$ Noe Alvarado-Vásquez, ${ }^{2}$ \\ A. Rosalía Montes-Vizuet, ${ }^{1}$ J. R. Velázquez-Rodriguez, ${ }^{1}$ M. Carmen Jimenez-Martinez, ${ }^{3}$ \\ and Luis Manuel Teran-Juárez ${ }^{1}$ \\ ${ }^{1}$ Department of Immunogenetics and Allergy, Instituto Nacional de Enfermedades Respiratorias, Calzada Tlalpan 4502, \\ 14080 Mexico, DF, Mexico \\ ${ }^{2}$ Department of Biochemistry, Instituto Nacional de Enfermedades Respiratorias, Calzada Tlalpan 4502, \\ 14080 Mexico, DF, Mexico \\ ${ }^{3}$ Department of Immunology, Research Unit, Institute of Ophthalmology, Foundation Conde de Valenciana, \\ 06800 Mexico, DF, Mexico
}

Correspondence should be addressed to Ma. Cristina Negrete-Garcia, crisdanmara@yahoo.com

Received 31 October 2011; Accepted 22 January 2012

Academic Editor: Ryuji Yasumatsu

Copyright (C) 2012 Ma. Cristina Negrete-Garcia et al. This is an open access article distributed under the Creative Commons Attribution License, which permits unrestricted use, distribution, and reproduction in any medium, provided the original work is properly cited.

\begin{abstract}
The aim of this work was to determine the presence of galectin-10 in nasal lavage fluid (NLF) of patients with aspirin-sensitive respiratory disease (ASRD) before and after challenge with L-ASA (aspirin) by ELISA. Fifteen ASRD patients, ten aspirin-tolerant asthmatics (ATA), and fifteen healthy controls (HC) were studied. The baseline presence of Galectin-10 in PBMC was determined using real time PCR. Galectin-10 was evaluated in tissue of nasal polyps by western blot. Our results showed a lower expression in PBMC of ASRD patients than in ATA and healthy controls. However, a higher concentration of galectin-10 in NLF was found in ASRD patients before and after L-ASA challenge; western blot confirmed a high expression of galectin-10 in tissue from nasal polyps obtained from ASRD patients. Our results suggest a probable role of galectin-10 in the inflammatory response observed in ASRD patients; however, confirmatory studies are needed.
\end{abstract}

\section{Introduction}

Aspirin-sensitive respiratory disease (ASRD) is a clinical syndrome characterized by a combination of nasal polyposis, chronic hypertrophic eosinophilic sinusitis, asthma and intolerance to aspirin or other nonsteroidal antiinflammatory drugs (NSAIDs). Ingestion of aspirin (L-ASA) and of most NSAIDs results in upper and/or lower respiratory reactions, including rhinitis, conjunctivitis, laryngospasm and bronchospasm [1]. The earliest symptoms are usually rhinorrhea with nasal congestion and progression to the lower respiratory tract with asthma and finally nasal polyposis [2]. In a study performed in the USA, the average age of onset was reported as 34 years, and it may be acquired between youth and mature age, with no ethnic predilection and rare familial associations. ASRD is more commonly reported in women than in men (57\% versus $43 \%$ ) [3].

Galectins are a growing family of $\beta$ galactoside-binding animal lectins. At least 12 galectins are present in humans [4]. It has been proposed that some galectins are secreted by an unorthodox mechanism to exert their extracellular function [5]. The wide distribution of galectins, with respect to species and tissues, suggests that they exert many different functions. The two most extensively studied galectins are galectin- 1 and galectin-3 [6], but little information exists about galectin10. It is well known that galectin-10 has been localized only in eosinophils and basophils; [7] however, a recent finding shows that galectin-10 is constitutively expressed in $\mathrm{CD} 4+\mathrm{CD} 25+$ regulatory T-cells in addition to playing a role for regulatory $\mathrm{T}$ cell function [8]. 
Currently, the knowledge about the presence of some galectins in epithelium, endothelium, and activiated tissue macrophages, cells that are involved in inflammation, it has led to many researchers to study the role of galectins in inflammatory processes [9]. Taking into account that the ASRD is a clinical syndrome associated with severe and chronic inflammation in both upper and lower airways and a recent finding [10], where the authors reported an overexpression of galectin-10 mRNA in peripheral blood of aspirin-induced asthma, we thought it was interesting to investigate whether galectin-10 was released in the nasal lavage fluid of a group of patients with ASRD before and after the challenge with the triggering agent (L-ASA) and to analyze its probable participation in the associated inflammatory process in ASRD.

\section{Material and Methods}

2.1. Subjects. Forty subjects from the Department of Immunogenetics and Allergy of our Institute, participated in this study, all of them were nonsmokers (Table 1). Their atopic status was investigated by skin-prick testing with different allergens including DPT, cat and dog dander, cocroach and trees-like Ligustrum vulgare or Alnus glutinosa. Neither oral corticosteroids nor antileukotrienes were given to patients 4 weeks before the study and $\beta 2$-agonists were withdrawn $48 \mathrm{Ih}$ before the study. Aspirin (L-ASA)sensitivity was established by clinical history and a nasal L-ASA challenge [11]. Before the challenge, all patients were examined with anterior rhinoscopy to evaluate the presence of nasal polyps. Five of the 15 L-ASA sensitive patients had small nasal polyps (Lund-Mackay score = 1). Patients with nasal polyps grades 2 and 3 did not participate in the study, because they could not undergo reliable rhinomanometry measurements [12]. This study was approved by the Institutional Ethics Committee and all patients gave their signed informed consent.

2.2. Study Design. Subjects were divided into three groups: (1) 15 L-ASA-sensitive asthmatics (ASRD), (2) 10 aspirintolerant asthmatics (ATA), and (3) 15 healthy controls (HC). The ASRD group had been diagnosed previously by both clinical history and a positive response to a nasal L-ASA challenge (from $25 \mathrm{mg}$ to $100 \mathrm{mg}$, according to the clinical response). A baseline nasal lavage and a peripheral blood sample were carried out in all subjects during the screening visit. Subsequently, nasal lavage fluid (NLF) was obtained pre- and postnasal challenge with L-ASA [13], which was used for the detection of Galectin-10 by ELISA.

2.3. Nasal L-ASA Challenge. A nasal L-ASA challenge was performed using a modified protocol described by Casadevall et al. [11]. The nasal challenge was performed with a total dose of $25 \mathrm{mg}$ of L-ASA (Aspisol, Bayer Germany), $12.5 \mathrm{mg}$ L-ASA was instilled in each nostril and on each inferior turbinate. The nasal response was evaluated by rhinomanometry and clinical response by scoring the subjective nasal symptoms using a visual analogue scale ranging from 0 (no symptoms) to 30 (severe symptoms) as described previously [14]. The clinical symptoms score included rhinorrhea, nasal blockage, itching of the nose, and palate and/or throat and sneezing. The positive nasal reaction was defined as the appearance of nasal symptoms such as rhinorrhea, nasal congestion, sneezing, and a $25 \%$ decrease of the total nasal flow value, as compared with the baseline measurement or a $40 \%$ bilateral decline of inspiratory nasal flow, as compared with the baseline value assessed by rhinomanometry. Subjects with baseline nasal inspiratory flow of $250 \mathrm{~mL} / \mathrm{s}$ did not participate in the study. The bronchial response was also evaluated by performing spirometry.

Nasal lavage fluid (NLF), blood, and tissue specimens from HC, ATA, and ASRD subjects were collected under rules approved by the institutional Bioethics Committee.

2.4. mRNA Expression by Quantitative Real-Time RT-PCR. RNA was extracted from $8 \times 10^{6}$ PBMC using TRIZOL (Gibco BRL, Gaithersburg, MD) according to manufacturer's instructions. RNA was reverse transcribed into cDNA using the ThermoScript RT-PCR system (Invitrogen, Carlsbad, CA, USA). Galectin-10 mRNA levels were quantified by realtime RT-PCR (qRT-PCR) using TaqMan Gene Expression Assay (Applied Biosystems, Tokio, Japan) on a StepOnePlus Real-Time PCR System (Applied Biosystems) according to manufacturer's instructions. The relative quantification method [15] was used to measure the amounts of Galecin-10, normalized to $18 \mathrm{~s}$ rRNA as endogenous control. The results were analyzed with the software ABI PRISM 7700 Sequence Detection System.

2.5. Double Antibody Solid Phase Immunoassay (ELISA). Measurement of galectin-10 was performed using a double antibody solid phase immunoassay (ELISA) developed in our laboratory. A human eosinophil cellular protein extract from a patient's blood with eosinophilia was used as positive control a human. Briefly, a monoclonal antibody to galectin-10 (Abcam, Cambridge UK) was incubated overnight at $4^{\circ} \mathrm{C}$ in an immunosorbent plate ( $R \& D$ Systems, Minneapolis MN, USA). The plate was blocked with BSA $(1 \%, 2 \mathrm{~h}, \mathrm{RT})$, and $100 \mu \mathrm{L}$ of nasal lavage fluid (NLF) or positive control was added, each sample was evaluated in triplicate and incubated overnight at $4^{\circ} \mathrm{C}$. Later, the plate was washed four times with phosphate-buffer saline (PBS) containing $0.05 \%$ Tween 20 and then, polyclonal goat antihuman galectin-10 antibody $1: 100$ (R\&D Systems) was added to each well $(2 \mathrm{~h})$. After washing with PBS-Tween 20 , we added a conjugate of donkey anti-goat biotinylated $1: 300$ (Sigma St. Louis, MO, USA) (2 h, RT). To evidence the reaction, $100 \mu \mathrm{L} /$ well of ExtrAvidin-Peroxidase $1: 500$ (Sigma) was added for 30 minutes. The plate was washed again and the immunoenzymatic reaction was revealed with tetramethylbenzidine (TMB) substrate (Sigma-Aldrich St. Louis, MO, USA). The absorbance was measured at $450 \mathrm{~nm}$ in an ELISA plate reader (Benchmark, Bio-Rad, Hercules, CA,USA). 
TABLE 1: Clinical characteristics of the study group.

\begin{tabular}{lccc}
\hline & HC & ATA & ASRD \\
\hline Subjects $(n)$ & 15 & $39(14-62)$ & 15 \\
AGE (years) & $23(21-34)$ & $4: 6$ & $47(28-74)$ \\
Gender M:F & $8: 7$ & 30 & $2: 13$ \\
Atopic $(\%)$ & 0 & $0.52 \pm 0.26$ & 47 \\
Blood Eosinophiis $\left(\times 10^{3} / \mathrm{mm}^{3}\right)$ & $0.17 \pm 0.16$ & $229.5 \pm 438.2$ & $0.50 \pm 0.42^{*}$ \\
IgE $(\mathrm{IU} / \mathrm{mL})$ & $76.8 \pm 65.4$ & 0 & $267.8 \pm 320.7$ \\
Lisil-aspirin challenge $(+)$ & 0 & $3.0 \pm 2$ & 15 \\
Methacholine PC20 $(\mathrm{mg} / \mathrm{mL})$ & $>32$ & $103 \pm 22$ & $2.5 \pm 1$ \\
Mean basal FEV $(\%$ predicted) & $107 \pm 6$ & & $97 \pm 12$ \\
\hline
\end{tabular}

HC: Healthy Controls.

ATA: Aspirin-Tolerant Asthmatics.

ASRD: Aspirin-Sensitive Respiratory Disease patients.

FEV: Forced-expiratory-volume.

${ }^{*} P>0.05$ ASRD versus ATA.

2.6. Western Blot. To evaluate the presence of galectin-10 in tissue samples, we performed a western blott with the protein extract of polyps obtained from ASRD and ATA patients. Tissue of nasal mucosa without inflammatory process was used as negative control. Nasal tissue extracts were prepared with cold lysis buffer (2 M Tris, pH 7.5, 0.15 M NaCl, 0.05 M NaF). Each sample was centrifuged at 13,000 rpm (Centrifuge Hermle Z232K, Hermle LaborTechnik, GmbH, Germany) for one minute at $4^{\circ} \mathrm{C}$. The supernatant was separated and the total protein concentration was determined with the Pierce BCA Protein assay kit (Thermo Scientific). Proteins (previously adjusted to $30 \mu \mathrm{g}$ ) were separated on $12 \%$ SDS Laemmli gels [16]. After electrophoresis, the proteins were transferred onto a polyvinyl difluoride membrane (BioRad), the membrane was incubated with 3\% BSA for 2 hours and then incubated with a monoclonal antibody to galectin-10 (Abcam, Cambridge, UK, 1:200) overnight at $4^{\circ} \mathrm{C}$. Immunodetection was performed incubating with a monoclonal anti-mouse biotinylated antibody and the Streptavidin-Peroxidase conjugate $(1: 1000)$ (Sigma) for 30 minutes; afterwards, the membrane was washed and incubated with DAB (Vector Laboratories, Burlingame, CA, USA).

2.7. Statistical Analysis. Statistical analysis was performed using Mann Whitney test, (GraphPad Prism 5, from GraphPad software, Inc. CA, USA). $P \leq 0.05$ was considered statistically significant. A post-hoc analysis of the sample size using $\mathrm{G}$ power (version 3.0.10) showed that 15 ASRD and 10 ATA subjects would have sufficient power $(80 \%)$ to test our hypothesis.

\section{Results}

3.1. Clinical Findings. Intranasal challenge with L-ASAinduced rhinorrhea, nasal congestion, and sneezing symptoms lasted up to $2 \mathrm{~h}$ in all ASA-sensitive patients. Following L-ASA challenge, a significant decline in the mean nasal inspiratory flow in ASA-sensitive patients was observed. Absence of clinical response to L-ASA was observed in

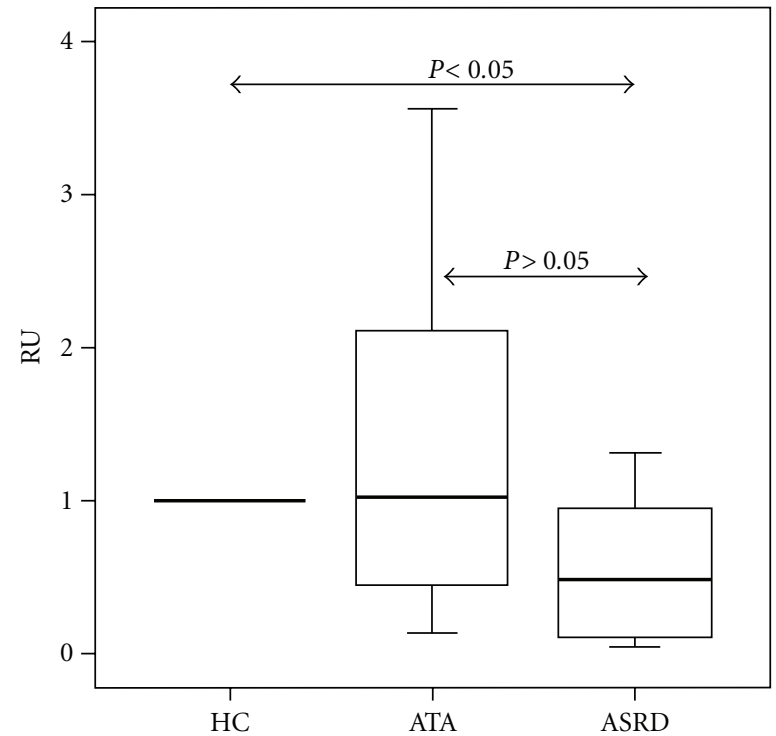

FIGURE 1: Relative quantification (RU:Relative Units) of galectin10 gene expression in PBMC with respect to healthy controls (HC) in patients with aspirin sensitive respiratory disease (ASRD) and aspirin-tolerant asthma (ATA).

both aspirin-tolerant asthmatics (ATA) and healthy controls (HC).

3.2. Gene-Expression of Galectin-10. We analyzed the galectin-10 gene expression in PBMC by real time PCR (Figure 1). The values were determined with respect to the healthy controls. A lower expression of galectin-10 gene was observed in ASRD with respect to ATA patients $(0.681 \pm 0.733$ versus $1.262 \pm 1.107)$.

3.3. Galectin-10 in Nasal Lavage Fluid. A higher baseline concentration of galectin-10 was observed in the NLF from ASRD and ATA patients with respect to the HC $(0.045 \pm$ $0.046,0.034 \pm 0.048$ versus $0.015 \pm 0.011$, resp.) (Figure 2). 


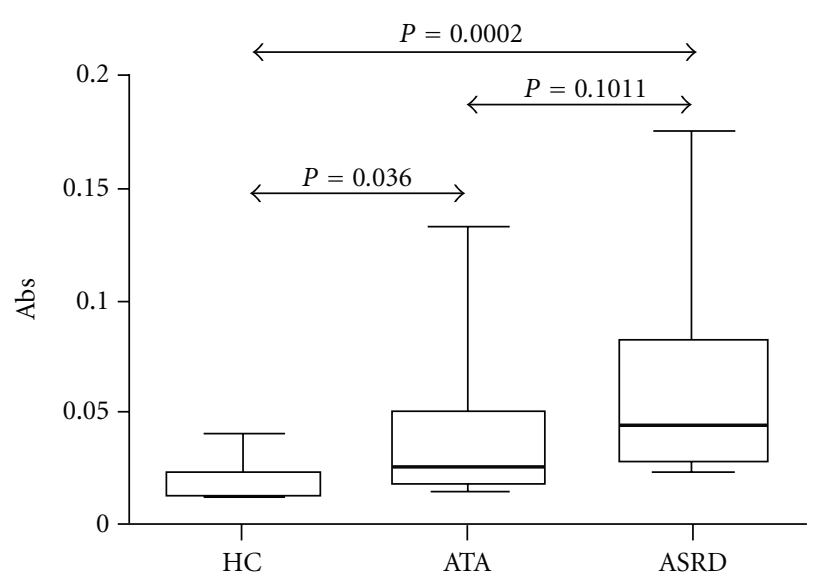

Figure 2: Determination of galectin-10 by ELISA at baseline in nasal lavage fluid of aspirin sensitive respiratory disease patients (ASRD), aspirin-tolerant asthmatics (ATA) and healthy controls (HC).

Interestingly, when we compared the pre- and postnasal LASA-challenge galectin-10 levels, significant differences in the concentration of galectin-10 were observed (Figure 3) (ASRD: $0.045 \pm 0.046$ versus $0.114 \pm 0.064$, ATA: $0.027 \pm$ 0.039 versus $0.068 \pm 0.059$ and HC: $0.015 \pm 0.010$ versus $0.044 \pm 0.014)$; these differences became more evident when comparing between ASRD and ATA patients $(P<0.0041$ versus $P<0.05)$.

3.4. Detection of Galecin-10 in Nasal Tissue by Immunoblot. Galectin-10 expression in nasal tissue was investigated by immunoblot using tissue from nasal polyps of ASRD and ATA patients and comparing their values versus healthy nasal mucosa tissue. Protein extract of eosinophils was used as positive control (Figure 4). Nasal polyps from the three different patients with ASRD and ATA were evaluated. Results show a higher expression of galectin-10 in patients with ASRD when compared with ATA patients and healthy nasal tissue. In healthy mucosa tissue, a lower galectin-10 expression was observed. This higher expression of galectin10 in patients with ASRD diagnosis may be probably a consequence of the more aggressive inflammatory process observed in this disease.

\section{Discussion}

This is the first study that shows the release of galectin-10 in nasal fluid lavage (NLF) of aspirin-sensitive respiratory disease (ASRD) patients before and after nasally challenged with L-ASA. The galectins family include 15 members [4, 17], which are $\beta$-galactosides-binding animal lectins [18]. Galectins have been associated with the innate and adaptive immune function $[19,20]$, as well as with cancer, immunity, and inflammatory responses [20,21]. Galectin-10 or Charcot Leyden crystal protein (CLC) has been previously related with the inflammatory process [6] and, recently also, it has been found in patients with allergic rhinitis [22]. However,

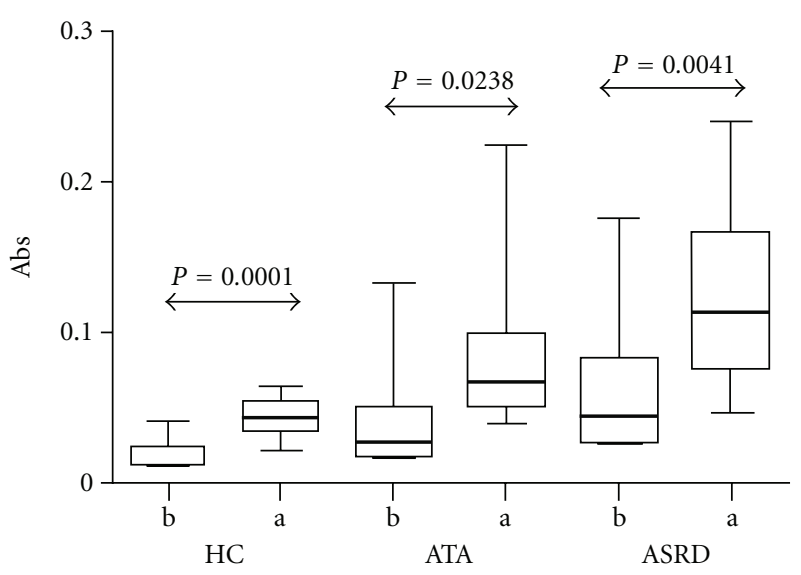

FIGURE 3: Comparison of galectin-10 levels before (b) and after (a) nasal challenge with L-ASA in nasal fluid lavage of aspirin-sensitive respiratory disease patients (ASRD), aspirin-tolerant asthmatics (ATA) and healthy controls (HC).

its function in the cell is still only partially understood. In this work, the expression of galectin-10 by real time PCR was determined in PBMC obtained from patients with ASRD. Recently, Devouassoux and cols. (2008) [10] reported an overexpression of mRNA galectin-10 in whole blood samples from patients with ASRD in absence of challenge with Laspirin, and they suggested the importance of galectin-10 in the accurate diagnosis of aspirin-induced asthma. Our results, however, showed a minor baseline expression of galectin-10 in PBMC from ASRD patients. It is probable that the observed differences in the expression of galectin10 could be an effect of the purification process of RNA [23], or due to individual differences in the galectin-10 geneexpression patterns as a product of the evaluated patient's age [24]. Additionally, it is important to highlight that the diagnosis of ASRD in the group of patients sutudied by Devouassoux was not made with the aspirin challenge test, regarded as decisive for the correct diagnosis of ASRD [25].

In this investigation, we also analyzed the presence of galectin-10 in healthy nasal tissue and nasal polyps extracts from ASRD and ATA patients by western blot. Our results showed a higher expression of galectin-10 in nasal polyps of patients with ASRD with respect to the ATA or healthy nasal tissue subjects. The presence of galectin-10 was confirmed using protein eosinophil extract as a positive control. Previously, the galectin-10 protein had been found in diverse tissues, body fluids, or cells involved with the inflammatory response, like eosinophils and basophils [26], as well as in inflamed nasal tissue with allergic rhinitis [27]. However, we do not know about any report about Galectin-10 in nasal polyps of ASRD subjects. We know that the presence of nasal polyps in ASRD is the ultimate manifestation of a chronic inflamatory process with the presence of activated eosinophils and mast cells [28]; therefore, we could infer that galectin-10 could be helping to perpetuate the inflammatory process in this site. It is relevant to mention that galectin-10 or Charcot-Leyden crystals contain the enzyme lysolecithin acylhydrolase, which is one of several proteins involved 


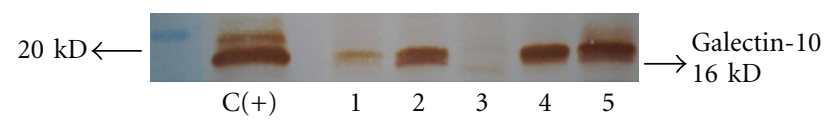

FIgURE 4: Western blot analysis of galectin-10 in supernatant of lysed nasal polyp from an aspirin-tolerant asthma polyp (lane 1), aspirin sensitive respiratory disease nasal polyps (lane 2, 4, and 5) and nasal mucosa as a tissue control without inflammatory process (lane 3). C(+) protein extract of eosinophils. (First lane, molecular weight markers).

in the eosinophil's immune functions [27]. Unfortunately, this enzyme also has the ability to damage the respiratory epithelium and to increase the vascular permeability [29, 30 ], which permits us to support its role in the chronic inflammatory response [31].

In this work we studied the levels of galectin-10 in nasal lavage fluid (NLF), before and after nasal challenge with L-aspirin. At baseline, the results evidenced higher concentrations of galectin-10 in NLF from patients with ASRD than in that from ATA and healthy subjects. After the challenge with L-aspirin, the levels of galectin-10 in the NLF behaved similarly; however, these differences were not significant between ASRD and ATA patients. We suggest that, after L-aspirin nasal challenge, the eosinophils migrate to the inflammation site in the nose, where they are activated and acquire the capacity to secrete their granule contents, increasing the levels of galectin-10 mainly in the ASRD group. In addition, we recently observed an increase in the concentration of eosinophil cationic protein (ECP) in NFL of aspirin-sensitive subjects versus healthy controls after nasal challenge with L-ASA [32], which confirms the release of mediators derived of eosinophils in the nasal fluid.

Previously, Ghafouri and cols, in a proteomic study [22], reported the presence of galectin-10 in nasal lavage fluid (NLF) from patients with seasonal allergic rhinitis. This fact supports the possibility that galectin-10 plays a role in the exacerbation of the inflammatory response, as well as its potential utility in the correct diagnosis of ASRD. However, in spite of this finding, the role(s) of this galectin in the eosinophil, basophil, or associated inflammatory processes still needs to be established. Nevertheless, the results obtained in this work suggest the role of galectin-10 in the early inflammatory response in ASRD patients, which could be a useful factor for the accurate diagnosis of the disease.

\section{References}

[1] D. D. Stevenson and A. Szczeklik, "Clinical and pathologic perspectives on aspirin sensitivity and asthma," Journal of Allergy and Clinical Immunology, vol. 118, no. 4, pp. 773-786, 2006.

[2] M. P. Berges-Gimeno, R. A. Simon, and D. D. Stevenson, "The natural history and clinical characteristics of aspirinexacerbated respiratory disease," Annals of Allergy, Asthma and Immunology, vol. 89, no. 5, pp. 474-478, 2002.

[3] A. Szczeklik, E. Nizankowska, and M. Duplaga, "Natural history of aspirin-induced asthma. AIANE Investigators.
European Network on Aspirin-Induced Asthma," European Respiratory Journal, vol. 16, no. 3, pp. 432-436, 2000.

[4] R. Y. Yang, G. A. Rabinovich, and F. T. Liu, "Galectins: structure, function and therapeutic potential," Expert Reviews in Molecular Medicine, vol. 10 article e17, 2008.

[5] D. N. W. Cooper and S. H. Barondes, "God must love galectins; he made so many of them," Glycobiology, vol. 9, no. 10, pp. 979-984, 1999.

[6] J. Almkvist and A. Karlsson, "Galectins as inflammatory mediators," Glycoconjugate Journal, vol. 19, no. 7-9, pp. 575$581,2002$.

[7] S. J. Ackerman, G. J. Weil, and G. J. Gleich, "Formation of Charcot-Leyden crystals by human basophils," Journal of Experimental Medicine, vol. 155, no. 6, pp. 1597-1609, 1982.

[8] J. Kubach, P. Lutter, T. Bopp et al., "Human $\mathrm{CD} 4^{+} \mathrm{CD} 25^{+}$ regulatory $\mathrm{T}$ cells: proteome analysis identifies galectin-10 as a novel marker essential for their anergy and suppressive function," Blood, vol. 110, no. 5, pp. 1550-1558, 2007.

[9] F. T. Liu, "Galectins: a new family of regulators of inflammation,” Clinical Immunology, vol. 97, no. 2, pp. 79-88, 2000.

[10] G. Devouassoux, A. Pachot, L. Laforest et al., "Galectin10 mRNA is overexpressed in peripheral blood of aspirininduced asthma," Allergy, vol. 63, no. 1, pp. 125-131, 2008.

[11] J. Casadevall, P. J. Ventura, J. Mullol, and C. Picado, "Intranasal challenge with aspirin in the diagnosis of aspirin intolerant asthma: evaluation of nasal response by acoustic rhinometry," Thorax, vol. 55, no. 11, pp. 921-924, 2000.

[12] M. Milewski, L. Mastalerz, E. Nizankowska, and A. Szczeklik, "Nasal provocation test with lysine-aspirin for diagnosis of aspirin-sensitive asthma," Journal of Allergy and Clinical Immunology, vol. 101, no. 5, pp. 581-586, 1998.

[13] E. Nizankowska-Mogilnicka, G. Bochenek, L. Mastalerz et al., "EAACI/GA2LEN guideline: aspirin provocation tests for diagnosis of aspirin hypersensitivity," Allergy, vol. 62, no. 10, pp. 1111-1118, 2007.

[14] R. E. Rojas, B. Y. Garfias, M. M. Jiménez et al., "Cell surface markers in patients with allergic rhinitis versus Der $\mathrm{p}$ and Der f challenge," Revista Alergia Mexico, vol. 47, no. 6, pp. 190-196, 2000.

[15] T. D. Schmittgen and K. J. Livak, "Analyzing real-time PCR data by the comparative CT method," Nature Protocols, vol. 3, no. 6, pp. 1101-1108, 2008.

[16] U. K. Laemmli, "Cleavage of structural proteins during the assembly of the head of bacteriophage T4," Nature, vol. 227, no. 5259, pp. 680-685, 1970.

[17] G. A. Rabinovich, F. T. Liu, M. Hirashima, and A. Anderson, "An emerging role for galectins in tuning the immune response: lessons from experimental models of inflammatory disease, autoimmunity and cancer," Scandinavian Journal of Immunology, vol. 66, no. 2-3, pp. 143-158, 2007.

[18] F. T. Liu and G. A. Rabinovich, "Galectins: regulators of acute and chronic inflammation," Annals of the New York Academy of Sciences, vol. 1183, pp. 158-182, 2010.

[19] D. Paclik, L. Werner, O. Guckelberger, B. Wiedenmann, and A. Sturm, "Galectins distinctively regulate central monocyte and macrophage function," Cellular Immunology, vol. 271, no. 1, pp. 97-103, 2011.

[20] G. A. Rabinovich, N. Rubinstein, and M. A. Toscano, "Role of galectins in inflammatory and immunomodulatory processes," Biochimica et Biophysica Acta, vol. 1572, no. 2-3, pp. 274-284, 2002. 
[21] H. M. Strik, M. Kolodziej, W. Oertel, and J. Bäsecke, "Glycobiology in malignant gliomas: expression and functions of galectins and possible therapeuticoptions," Current Pharmaceutical Biotechnology. In press.

[22] B. Ghafouri, K. Irander, J. Lindbom, C. Tagesson, and M. Lindahl, "Comparative proteomics of nasal fluid in seasonal allergic rhinitis," Journal of Proteome Research, vol. 5, no. 2, pp. 330-338, 2006.

[23] L. Rainen, U. Oelmueller, S. Jurgensen et al., "Stabilization of mRNA expression in whole blood samples," Clinical Chemistry, vol. 48, no. 11, pp. 1883-1890, 2002.

[24] M. Dias-Baruffi, S. R. Stowell, S. C. Song et al., "Differential expression of immunomodulatory galectin-1 in peripheral leukocytes and adult tissues and its cytosolic organization in striated muscle," Glycobiology, vol. 20, no. 5, Article ID cwp203, pp. 507-520, 2010.

[25] R. U. Lee and D. D. Stevenson, "Aspirin-exacerbated respiratory disease: evaluation and management," Allergy, Asthma and Immunology Research, vol. 3, no. 1, pp. 3-10, 2010.

[26] S. J. Ackerman, G. J. Swaminathan, D. D. Leonidas et al., "Leonidas DD, Savage MP, Patrick S, Parry S, Nightingale T, Acharya KR. Structural biology of Charcot-Leyden crystal protein (Galectin-10): new insights into an old protein," Respiratory Medicine, vol. 94, pp. 1014-1016, 2000.

[27] H. S. Park, D. H. Nahm, K. Park, K. S. Suh, and H. E. Yim, "Immunohistochemical characterization of cellular infiltrate in nasal polyp from aspirin-sensitive asthmatic patients," Annals of Allergy, Asthma and Immunology, vol. 81, no. 3, pp. 219-224, 1998.

[28] L. Pantanowitz and K. Balogh, "Charcot-Leyden crystals: pathology and diagnostic utility," Ear, Nose and Throat Journal, vol. 83, no. 7, pp. 489-490, 2004.

[29] S. L. Harlin, D. G. Ansel, S. R. Lane, J. Myers, G. M. Kephart, and G. J. Gleich, "A clinical and pathologic study of chronic sinusitis: the role of the eosinophil," Journal of Allergy and Clinical Immunology, vol. 81, no. 5 I, pp. 867-875, 1988.

[30] F. Huang, P. V. Subbaiah, O. Holian et al., "Lysophosphatidylcholine increases endothelial permeability: role of PKC $\alpha$ and RhoA cross talk," American Journal of Physiology-Lung Cellular and Molecular Physiology, vol. 289, no. 2, pp. L176L185, 2005.

[31] A. Perić, D. Vojvodić, V. Radulović, B. VukomanovićDurdević, A. V. Perić, and O. Miljanović, "Proinflammatory cytokine levels in nasal fluid as indicators of severity of nasal polyposis," Acta clinica Croatica, vol. 49, no. 4, pp. 395-403, 2010.

[32] A. Fuentes-Beltrán, R. Montes-Vizuet, E. Valencia-Maqueda, M. C. Negrete-García, M. D. L. García-Cruz, and L. M. Teran, "Chemokine CC-ligand 5 production and eosinophil activation into the upper airways of aspirin-sensitive patients," Clinical and Experimental Allergy, vol. 39, no. 4, pp. 491-499, 2009. 


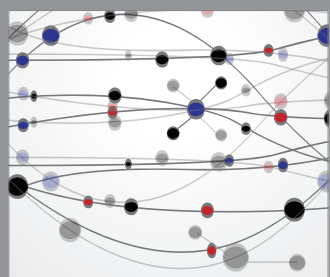

The Scientific World Journal
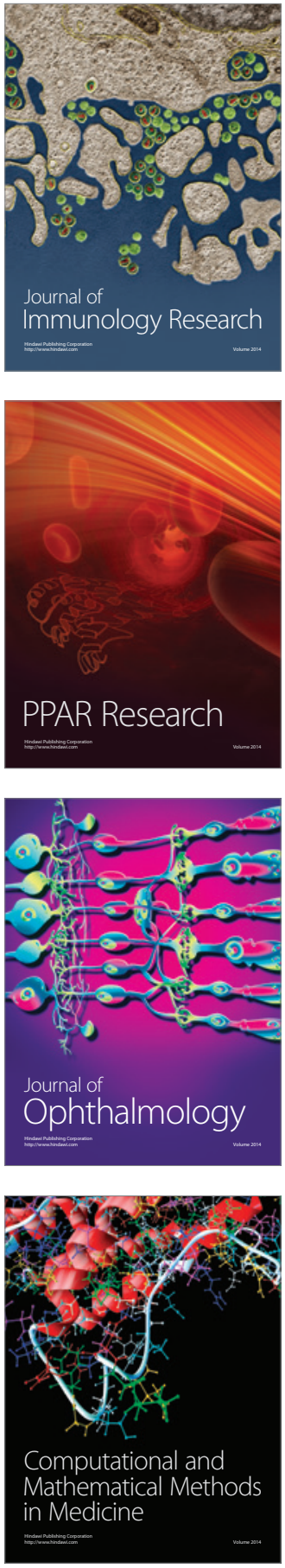

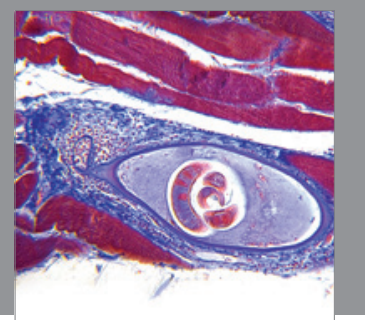

Gastroenterology

Research and Practice
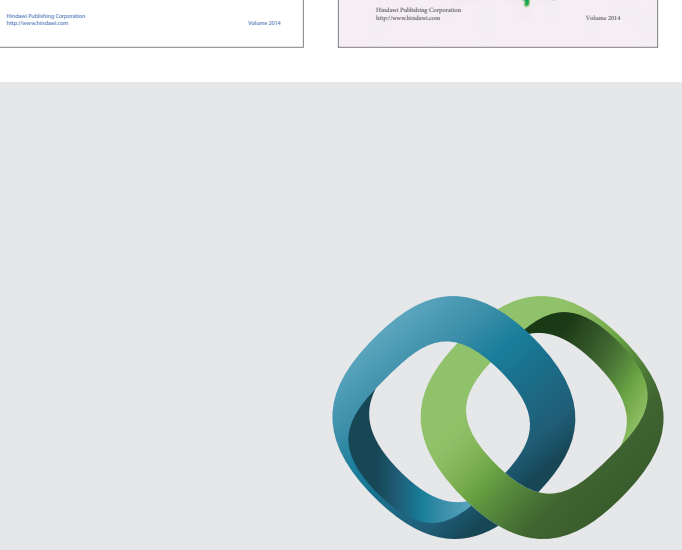

\section{Hindawi}

Submit your manuscripts at

http://www.hindawi.com
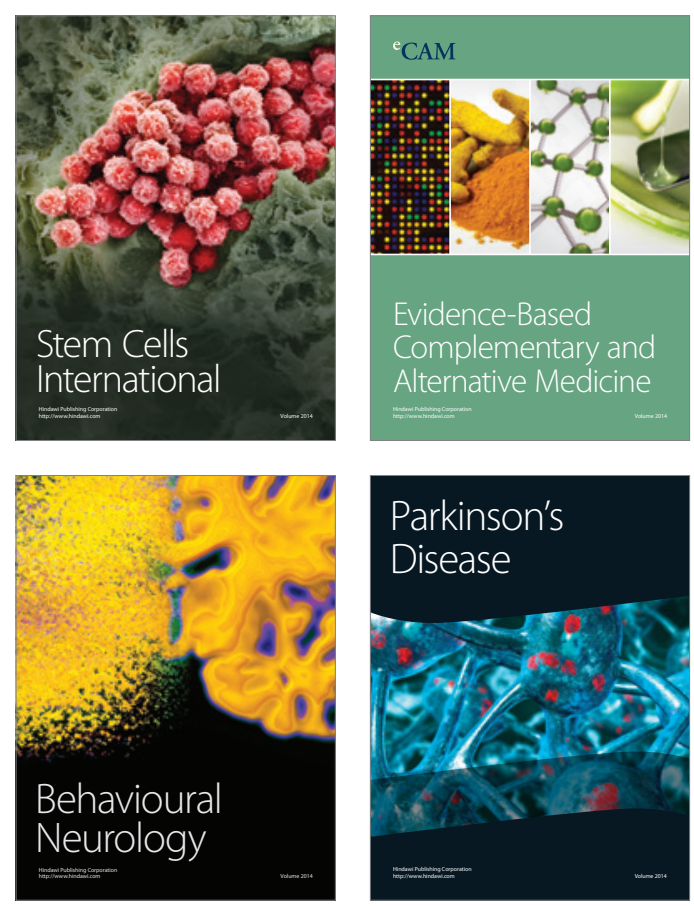

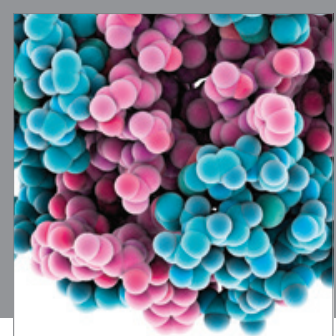

Journal of
Diabetes Research

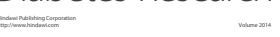

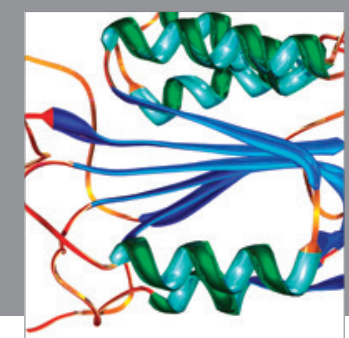

Disease Markers
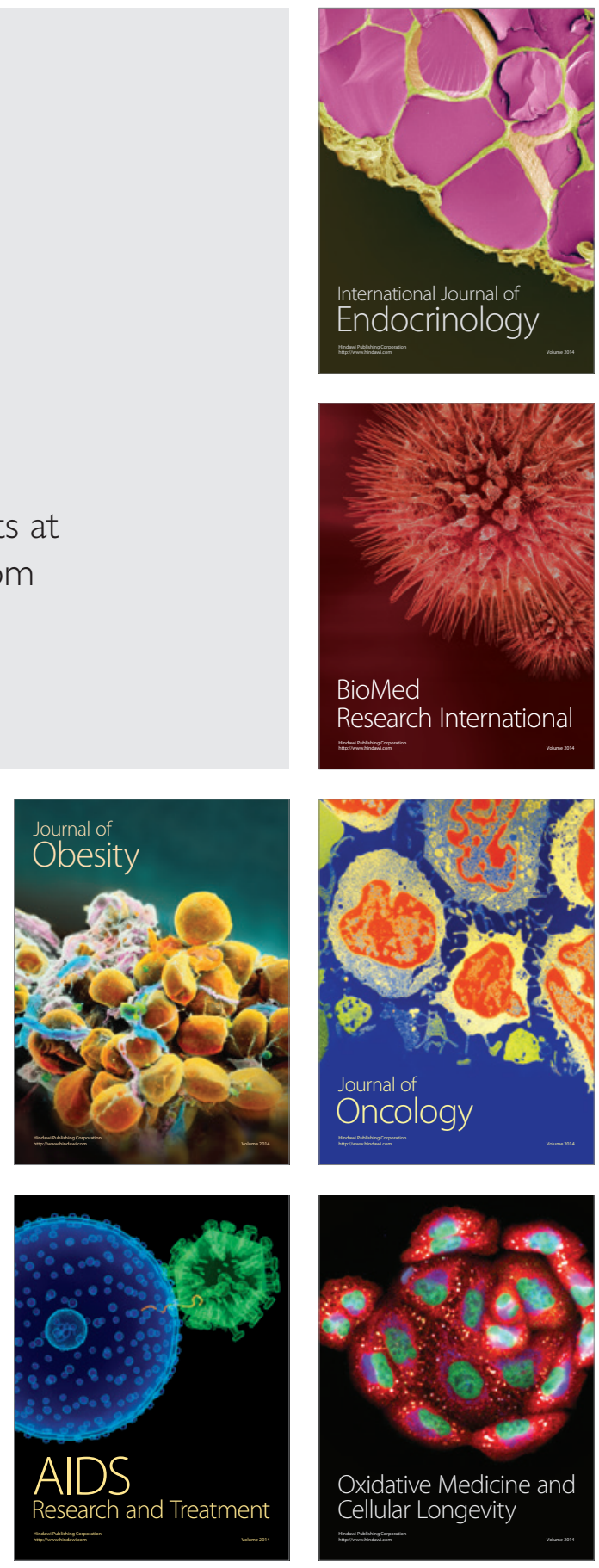